\title{
Increased expression of interleukin-1 receptor type 1 in active endometriotic lesions
}

\author{
C Lawson $^{1,2}$, M Al-Akoum $^{1,2}$, R Maheux $^{1,2}$ and A Akoum ${ }^{1,2}$ \\ ${ }^{1}$ Centre de Recherche, Hôpital Saint-François d'Assise, Centre Hospitalier Universitaire de Québec, Québec, Canada \\ and ${ }^{2}$ Département d'Obstétrique et Gynécologie, Faculté de Médecine, Université Laval, Québec, Canada
}

Correspondence should be addressed to A Akoum who is now at Unité d'Endocrinologie de la Reproduction, Centre de Recherche, Hôpital Saint-François d'Assise, Centre Hospitalier Universitaire de Québec, 10 rue de l'Espinay, Local D0-711, Québec, Canada G1L 3L5; Email: ali.akoum@crsfa.ulaval.ca

\begin{abstract}
The establishment and progression of ectopic endometrial implants are dependent upon their interaction with and responsiveness to the stimuli present in their new environment. According to our and other previous studies, immune cells-derived cytokines, such as IL-1, may alone or in concert with estrogens, enhance the capability of ectopic endometrial cells to implant and develop into the host tissue. In the present study, immunohistochemical and dual immunofluorescence analyses showed that the functional signaling interleukin-1 receptor type 1 (IL-1RI) is expressed in endometriotic tissue, particularly in the glands, and identified endothelial cells, macrophages, and T-lymphocytes as cells having marked expression of IL-1 RI. The highest concentrations of IL-1 RI protein in endometriotic tissue, as evaluated using histological score (HSCORE) and measured by ELISA, were found in red endometriotic lesions as compared with typical black-blue or white lesions. Western blotting showed a significant increase in the levels of the $50 \mathrm{kDa}$ band, whose apparent molecular weight corresponds to the soluble form of IL-1 RI. RT-PCR analysis of IL-1 mRNA levels showed a pattern of expression comparable to that of the protein. Interestingly, IL-1RI expression was more significant in the proliferative than in the secretory phase of the menstrual cycle. Marked expression of IL-1RI, the functional signaling receptor that mediates cell activation by IL-1, in red endometriotic implants, which are highly vascularized and represent the earliest and most active forms of the disease, point to a higher cell receptivity for IL-1 in these lesions, a relationship with the activity of the disease and a possible involvement in the early steps of endometriotic tissue growth and development.
\end{abstract}

Reproduction (2007) 133 265-274

\section{Introduction}

Endometriosis is a common gynecological disease that affects approximately $10-20 \%$ of women of reproductive age and is defined by the presence and the growth of endometrial-like tissue outside the uterus, mainly in the peritoneal cavity (Olive \& Schwartz 1993). Common sites of growth include the ovary, the bladder, the intestine, and the pelvic peritoneum. Endometriotic implants resemble eutopic endometrium, histologically, and can in their active forms undergo endometrial-like cyclic menstrual changes with periodic bleeding. Although endometriosis is considered a benign proliferative disease, both mild and severe forms are frequently associated with abdominal pain, dysmenorrhea, dyspareunia, and infertility causing profound physical and psychological distress. The etiology of endometriosis is still not clearly elucidated, but appears to involve a complex interplay of multiple genetic, environmental, and immunological factors (Lebovic et al. 2001 a, Barlow \& Kennedy 2005, Ulukus \& Arici 2005).

Numerous endometriosis-associated immunological changes were detected in the eutopic endometrium and the peripheral blood (Giudice et al. 1998, Giudice 2003, D'Hooghe et al. 2004, Sharpe-Timms 2005), but were particularly observed locally in the peritoneal cavity where the disease often develops.

The peritoneal fluid of endometriosis patients was shown to contain elevated levels of autoantibodies, proinflammatory mediators, and inflammatory cells, especially activated macrophages. These cells are known to secrete growth factors and proinflammatory stimuli which may exacerbate the inflammatory reaction observed in the peritoneal cavity, but may also have a direct effect on ectopic endometrial cell growth and phenotype (Harada et al. 2001, Taylor et al. 2002, Bedaiwy \& Falcone 2003, Wu \& Ho 2003). 
Inflammation around and within active endometrial implants, and increased leukocyte infiltration and cytokine secretion as compared to eutopic endometrial tissue have widely been described (Halme et al. 1987, Hill et al. 1988, Tseng et al. 1996, Jolicoeur et al. 1998, Jones et al. 1998, Witz 2002, Wu \& Ho 2003). The secretion of proinflammatory and mitogenic proteins by endometriotic lesions and associated immune cells into the peritoneal environment may contribute to a cascade of events favoring tissue remodeling and invasion of the host tissue, angiogenesis and cell proliferation in the growing lesions and further chemoattraction of leukocytes to these foci of peritoneal inflammation. Cytokines are believed to participate in the induction and effector phases of immune and inflammatory reactions and to play an important role in the development of the endometriosis-related chronic inflammatory processes and tissue remodeling (Lebovic et al. 2001a, Taylor et al. 2002, Wu \& Ho 2003).

Interleukin (IL)-1 is part of a family of polypeptides composed of IL-1 $\alpha$; IL-1 $\beta$; and an inhibitor, IL-1 receptor antagonist (IL-1 ra). These components interact with two main receptors: interleukin-1 receptor type I (IL-1RI), the functional signaling receptor which is found primarily on T cells, endothelial cells, and macrophages, transduces signals in concert with the co-receptor IL-1 receptoraccessory protein (IL-1RAcP) and is crucial for IL-1mediated cell activation, and IL-1 receptor type II (IL-1RII), which is a decoy receptor with no signaling properties (Subramaniam et al. 2004).

Interleukin-1, a principal macrophage-derived and major proinflammatory cytokine, may play a central role in the integrated inflammatory cascade associated with endometriosis and in propagating endometriotic implants through a proinflammatory stimulus, synthesis of chemokines, growth, and angiogenic factors (Akoum et al. 1995, 1996, 2001, Lebovic et al. 2001 b). Increased concentrations of the cytokine were found in the peritoneal fluid of women with endometriosis (Fakih et al. 1987, Mori et al. 1992, Taketani et al. 1992) as well as in ectopic endometrial implants (Bergqvist et al. 2001). In our previous studies, endometriotic cells showed a marked secretion of monocyte chemotactic protein-1 (MCP-1), regulated on activation normal T-cell expressed and secreted (RANTES), IL-6 and IL-8 following exposure to IL-1, and displayed a remarkable sensitivity for IL-1 (Akoum et al. 1995, 1996, 2001, 2002). In keeping with our findings, data from Lebovic et al. (2000) suggest that the ability of IL-1 $\beta$ to activate an angiogenic phenotype in endometriotic stromal cells, but not in stromal cells from normal endometrium, is mediated by the functional signaling receptor IL-1RI.

The present study was undertaken to assess the expression of IL-1RI in endometriotic lesions, to identify the sites of expression, and to investigate whether such an expression varies according to the stage and the activity of the disease. Our study revealed a marked expression of IL-1RI in the red highly vascularized lesions, which are believed to represent the earliest and most active forms of the disease, as compared with the typical black-blue and the white lesions. Furthermore, our data showed more significant expression of IL-1RI in proliferative phase than in secretory phase endometriotic lesions, thereby revealing cycle phasedependent cell receptivity for IL-1 and a close relationship with the activity of the disease.

\section{Materials and Methods}

\section{Subjects}

Endometriotic tissue specimens used in this study were obtained from women $(n=53)$ who provided informed consent for a research protocol approved by SaintFrançois d'Assise Hospital Ethics Committee on Human Research. These patients were found to have endometriosis during laparoscopy or laparotomy, had no endometrial hyperplasia or neoplasia, and had not received any anti-inflammatory or hormonal medication during a period of at least 3 months before surgery. Endometriosis was staged according to the revised American Fertility Society classification system (Anonymous 1997). The cycle phase (proliferative or secretory) was determined according to the cycle history and confirmed by histological examination of endometrial biopsies using the criteria of Noyes et al. (1975). The mean age was $32.0 \pm 5.0$ years.

\section{Collection of endometriotic biopsies}

Endometriotic biopsies were immediately placed at $4{ }^{\circ} \mathrm{C}$ in sterile Hank's balanced salt solution (HBSS; GIBCO Invitrogen Corp.) containing $100 \mathrm{U} / \mathrm{ml}$ penicillin, $100 \mu \mathrm{g} / \mathrm{ml}$ streptomycin, and $0.25 \mu \mathrm{g} / \mathrm{ml}$ amphotericin, transported to the laboratory at which they were washed in HBSS at $4{ }^{\circ} \mathrm{C}$, snap frozen on dry ice, and kept at $-80^{\circ} \mathrm{C}$ in eppendorf tubes for western blot, ELISA, and RT-PCR analyses or embedded in paraffin for immunohistochemical studies.

For ELISA, 30 endometriotic biopsies were included. These biopsies were from women with endometriosis stage I (six red, five typical, and four white), stage II (two red, seven typical, and two white), and stages III and IV (one red, one typical and two white).

For immunohistochemical studies, 18 endometriotic biopsies were included. These biopsies were from women with endometriosis stage I (one red, one typical, and three white), stage II (five red and three typical), and stages III and IV (one red, two typical, and two white).

For western blot analysis, 25 endometriotic biopsies were included. These biopsies were from women with endometriosis stage I (two red and two typical), stage II (four red, seven typical, and two white), and stages III and IV (one red, five typical, and two white). 
For RT-PCR analysis, 30 endometriotic biopsies were included. These biopsies were from women with endometriosis stage I (five red, three typical, and five white), stage II (three red, six typical, and five white), and stages III and IV (one red and two white).

\section{Immunohistochemistry}

Paraffin-embedded tissue sections of $5 \mu \mathrm{m}$ were mounted on poly-L-lysine-coated microscope glass slides, deparaffinized in toluene, rehydrated through graded solutions of ethanol and water, and washed in PBS. Sections were then permeabilized in PBS-1\% Triton X-100 for $20 \mathrm{~min}$ at room temperature and treated with $0.3 \% \mathrm{H}_{2} \mathrm{O}_{2}$ in methanol for $20 \mathrm{~min}$ at room temperature to eliminate endogenous peroxidase. Thereafter, sections were incubated for $30 \mathrm{~min}$ at room temperature with normal rabbit serum $1.5 \%$ in PBS containing $0.2 \%$ BSA and $0.01 \%$ Tween 20) to block non-specific binding, then 1 h at $37^{\circ} \mathrm{C}$ in a humidified chamber with a polyclonal goat antihuman IL-1 receptor type I (primary antibody; R\&D Systems, Minneapolis, MN, USA) used at $15 \mu \mathrm{g} / \mathrm{ml}$ in the $\mathrm{PBS} / \mathrm{BSA} / T$ ween 20 solution. After three rinses with $\mathrm{PBS} / 0.1 \%$ Tween 20 , tissue sections were incubated for $45 \mathrm{~min}$ at room temperature with a biotin-conjugated rabbit anti-goat IgG $(\mathrm{H}+\mathrm{L}$; Jackson ImmunoResearch Laboratories Inc., West Grove, PA, USA; 1:1000 dilution in PBS/BSA/Tween 20), rinsed with PBS/0.1\% Tween 20, then incubated for $30 \mathrm{~min}$ at room temperature with peroxidase-conjugated streptavidin (Jackson ImmunoResearch Laboratories Inc.; 1:500 dilution in PBS/BSA/ Tween 20). After a final PBS rinse, the sections were stained for $20 \mathrm{~min}$ with 3,3'-diaminobenzidine (DAB; Sigma-Aldrich Canada Ltd; $0.5 \mathrm{mg}$ DAB/0.03\% $\mathrm{H}_{2} \mathrm{O}_{2}$ in $\mathrm{PBS})$, rinsed in water, counterstained with hematoxylin and mounted in Mowiol (Calbiochem, La Jolla, CA, USA). Sections incubated with an equivalent concentration of normal goat immunoglobulins instead of the primary antibody were included as negative controls in all experiments. Normal endometrial tissue, which according to our previous studies, expresses IL-1RI receptor (Bigonnesse et al. 2001), was used as positive control. All sections were examined on a blind basis using a Leica microscope (mikroskopie und systeme $\mathrm{GmbH}$, model DMRB, Leica Corp., Postfach, Wetzlar, Germany) with $40 \times$ objective. IL-1RI immunostaining was evaluated using a semi-quantitative histological score (HSCORE) which takes into account the distribution and the intensity of staining. The HSCORE was calculated with the following equation: $\mathrm{HSCORE}=\Sigma \mathrm{Pi}(i+1)$, where $i=$ intensity of staining with a value of 1,2 , or 3 (weak, moderate, or strong respectively) and $\mathrm{Pi}$ is the percentage of stained cells for each intensity, varying from 0 to $100 \%$. It is of note that endometriotic tissue sections showing no endometrial-like glandular structures were not included (four tissues out of 22, including one red, two typical, and one white lesions).

\section{Dual immunofluorescent staining}

Paraffin-embedded tissue sections were treated, then incubated for $30 \mathrm{~min}$ at room temperature with $\mathrm{PBS} / 5 \%$ BSA (blocking solution) and incubated for $1 \mathrm{~h}$ at $37^{\circ} \mathrm{C}$ with a polyclonal goat anti-human IL-1 receptor type I antibody (R\&D Systems), at $15 \mu \mathrm{g} / \mathrm{ml}$ in PBS/BSA/Tween as described earlier (immunohistochemistry section). After a PBS/0.05\% Tween 20 rinse, sections were incubated at room temperature for $90 \mathrm{~min}$ with one of the following antibodies: mouse monoclonal anti-human CD68 (DAKO Diagnostics Canada, Inc., Mississauga, ON, Canada; diluted 1:50 in PBS/BSA/Tween) to detect macrophages; mouse monoclonal anti-human CD3 (a gift from Dr W Mourad, Laval University, Quebec, Canada; diluted 1:100 in PBS/BSA/Tween) to detect T-lymphocytes; and mouse monoclonal anti-human von Willebrand factor (vWF; DAKO Diagnostics Canada, Inc.; diluted 1:25 in PBS/BSA/Tween) to detect endothelial cells. After a subsequent wash in PBS/0.05\% Tween 20, tissue sections were incubated simultaneously for $60 \mathrm{~min}$ at room temperature in the dark with fluorescein isothiocyanate-conjugated donkey anti-goat antibody (Jackson ImmunoResearch Laboratories, Inc.; diluted 1:50 in PBS/BSA/Tween) and Alexa Fluor 594 labeled goat anti-mouse antibody (Molecular Probes Inc., Eugene, OR, USA; diluted at $2 \mu \mathrm{g} / \mathrm{ml}$ in PBS/BSA/Tween). After a final wash in PBS/0.05\% Tween 20, slides were mounted in Mowiol containing 10\% para-phenylenediamine (Sigma-Aldrich Canada Ltd), an anti-fading agent, and observed under the microscope (Leica Corp.) equipped for fluorescence with a $100 \mathrm{~W}$ u.v. lamp and connected to an image analysis system (ISIS, Metasystems, Altlussheim, Germany).

\section{IL-1RI ELISA}

Proteins were extracted from frozen endometrial tissues. The tissues were directly homogenized with a microscale tissue grinder (Kontes, Vineland, NJ, USA) in a buffer containing $0.5 \%$ Triton X-100, $10 \mathrm{mmol} / \mathrm{I} \mathrm{HEPES}$ $(\mathrm{pH} 7.4), 150 \mathrm{mmol} / \mathrm{l} \mathrm{NaCl}, 2 \mathrm{mmol} / \mathrm{l}$ ethyleneglycoltetraacetic acid, $2 \mathrm{mmol} / \mathrm{l}$ ethylenediaminetetraacetic acid, $0.02 \% \mathrm{NaN}_{3}$, and a mixture of anti-proteases composed of $5 \mu \mathrm{mol} / /$ aprotinin, $63 \mu \mathrm{mol} / /$ leupeptin, and $3 \mathrm{mmol} / \mathrm{l}$ phenylmethylsulfonylfluoride (PMSF). Tissue homogenate was then incubated at $4{ }^{\circ} \mathrm{C}$ for $45 \mathrm{~min}$ under gentle shaking, and centrifuged at $11000 \mathrm{~g}$ for $30 \mathrm{~min}$ to recover the soluble extract, whose total protein concentration was determined using the Bio-Rad DC Protein Assay (Bio-Rad Laboratories Ltd). IL-1RI concentrations were measured using an ELISA procedure developed in the laboratory. This assay uses a mouse monoclonal anti-human IL-1RI antibody (capture antibody) that does not cross-react with rhIL1 RII (R \& D Systems) and a goat polyclonal anti-human IL-1RI antibody (detection antibody) that shows $5-10 \%$ 
cross-reactivity with rhlL-1RII (R\&D Systems). Briefly, 96-well plates were coated overnight at $4{ }^{\circ} \mathrm{C}$ with the mouse monoclonal anti-human IL-1RI antibody. Plates were washed four times with PBS containing $0.01 \%$ Tween 20 (washing buffer) and incubated $90 \mathrm{~min}$ at $37^{\circ} \mathrm{C}$ with different concentrations of human recombinant soluble IL-1RI (0-6.4 $\mathrm{ng} / \mathrm{ml}$; R\&D Systems), or with endometriotic tissue protein extracts diluted in $\mathrm{PBS} / 0.5 \%$ BSA. The plates were then washed and incubated for $60 \mathrm{~min}$ at $37^{\circ} \mathrm{C}$ with $\mathrm{PBS} / 3 \%$ BSA (blocking solution). After washing, the plates were incubated with a goat polyclonal anti-human IL-1RI for $1 \mathrm{~h}$ at $37^{\circ} \mathrm{C}$, washed again and incubated for $60 \mathrm{~min}$ at $37^{\circ} \mathrm{C}$ with a peroxidase-conjugated rabbit anti-goat antibody (Jackson ImmunoResearch Laboratories Inc.). After a final wash, $100 \mu \mathrm{l}$ TMB (3,3',5,5'-tetramethylbenzidine)-peroxidase substrate (Bio-Rad Laboratories $\mathrm{Ltd}$ ) was added to each well, the enzymatic reaction was terminated by the addition of $50 \mu \mathrm{l} 2 \mathrm{~N} \mathrm{H}_{2} \mathrm{SO}_{4}$ and the optical density was determined at $450 \mathrm{~nm}$. IL-1RI concentrations were calculated by interpolation from the standard curve. The sensitivity limit of the assay based on rhIL-1RI was 20-25 pg/ml, and no detection of rhIL-1RII was noted.

\section{Western blotting}

Frozen endometriotic tissues were directly homogenized with the use of a microscale tissue grinder (Kontes) in a buffer (pH 7.4) containing $0.5 \%$ Triton X-100, $10 \mathrm{mM}$ HEPES, $150 \mathrm{mM} \mathrm{NaCl}, 2 \mathrm{mM}$ ethyleneglycoltetraacetic acid (EGTA), $2 \mathrm{mM}$ ethylenediaminetetraacetic acid (EDTA), $0.02 \% \mathrm{NaN}_{3}$, and a mixture of anti-proteases composed of $5 \mu \mathrm{M}$ aprotinin, $63 \mu \mathrm{M}$ leupeptin, and $3 \mathrm{mM}$ PMSF. Tissue homogenate was then incubated at $4{ }^{\circ} \mathrm{C}$ for 45 min under gentle shaking, and centrifuged at $11000 \mathrm{~g}$ for $30 \mathrm{~min}$ to recover the soluble extract. Total protein concentration was determined using the Bio-Rad DC Protein Assay (Bio-Rad Laboratories Ltd). Proteins $(50 \mu \mathrm{g})$ from each extract were heated in a boiling bath for $5 \mathrm{~min}$ in $5 \times$ SDS sample buffer $(1.25 \mathrm{M}$ Tris- $\mathrm{HCl}$, $50 \%$ glycerol, $25 \% \beta$-mercaptoethanol, $10 \%$ SDS, and $0.01 \%$ bromophenol blue, $\mathrm{pH} 6.8$ ), separated by SDSPAGE in $10 \%$ acrylamide linear gradient slab gels and transferred onto $0.2 \mu \mathrm{m}$ nitrocellulose membranes (Schleicher \& Schuell, Keene, NH, USA) using electrophoretic transfer cell (Bio-Rad Laboratories Ltd). Human recombinant soluble IL-1RI (R\&D Systems) was used as a positive control.

Equal loading in each lane was confirmed by staining blots with Ponceau S (2\%). Nitrocellulose membranes were then immersed in PBS containing 5\% skimmed milk and $0.1 \%$ Tween 20 (blocking solution) for $1 \mathrm{~h}$ at $37^{\circ} \mathrm{C}$, cut into strips and incubated overnight at $4{ }^{\circ} \mathrm{C}$ with a mouse monoclonal anti-human IL-1 receptor type I (R\&D Systems; $2 \mu \mathrm{g} / \mathrm{ml}$ in PBS containing 1\% BSA and $0.1 \%$ Tween 20 ) or with normal rabbit immunoglobulins
(IgGs; R\&D Systems) at equivalent concentration. Thereafter, the strips were incubated for $45 \mathrm{~min}$ at $37^{\circ} \mathrm{C}$ with peroxidase-conjugated goat anti-mouse antibody (Jackson ImmunoResearch Laboratories Inc.; 1:3000 dilution in PBS/BSA/Tween 20). Membranes were also blotted with an anti- $\alpha$-actin antibody (1:1000 dilution in PBS/BSA/Tween 20; lowa University developmental studies hybridoma bank (DSHB). After three washes (10 min each in PBS/0.1\% Tween 20), the strips were incubated for $1 \mathrm{~min}$ with an ECL system: BM chemiluminescence blotting substrate (POD; Roche Diagnostics) and exposed to Biomax film (Kodak) from $30 \mathrm{~s}$ to $1 \mathrm{~min}$ for an optimal detection (all bands visible but not overexposed).

\section{Reverse transcriptase (RT)-PCR}

Total RNA was extracted from endometriotic tissue with TRIzol reagent according to the manufacturer's instructions (Invitrogen Life Technologies). Complementary deoxyribonucleic acid (cDNA) was synthesized using $500 \mathrm{ng}$ total cellular RNA and $2.5 \mu \mathrm{M}$ random hexamers in $20 \mu \mathrm{l}$ solution containing $50 \mathrm{mM} \mathrm{KCl}, 10 \mathrm{mM}$ Tris$\mathrm{HCl}, 5 \mathrm{mM} \mathrm{MgCl} 2,1 \mathrm{mM}$ each of dNTPs, $20 \mathrm{U}$ RNase inhibitor, and $50 \cup$ Reverse Transcriptase using Gene Amp PCR Core Kit (Perkin-Elmer, Foster City, CA, USA). The reaction was incubated at $25^{\circ} \mathrm{C}$ for $15 \mathrm{~min}, 42{ }^{\circ} \mathrm{C}$ for $30 \mathrm{~min}$, and $99^{\circ} \mathrm{C}$ for $5 \mathrm{~min}$.

For PCR analysis, we used $10 \%$ of the RT reaction volume as template in a final volume of $50 \mu \mathrm{l}$ with 25 pmol each IL-1RI primer (foward primer, $5^{\prime}$ GAT TCA GGA CAT TAC TAT TGC G 3'; reverse primer, 5' CTG GGA TCC CAA GTC TAC TTC C 3'; amplimer size $464 \mathrm{bp}), 0.2 \mathrm{mmol} / \mathrm{l} \mathrm{dNTPs}$, and $1 \mathrm{U}$ Vent DNA Polymerase (New England Biolabs Ltd, Mississauga, ON, Canada). Amplification was performed for 30 cycles of $30 \mathrm{~s}$ denaturation $\left(95^{\circ} \mathrm{C}\right), 30 \mathrm{~s}$ annealing $\left(50^{\circ} \mathrm{C}\right)$, and 1 min primer extension $\left(72{ }^{\circ} \mathrm{C}\right)$. These optimal conditions were determined following linearity tests using $2.5,5,10$, and $20 \%$ of RT reaction volume.

Amplification of genomic DNA with these primers did not produce a signal, suggesting that the amplification sites crossed at least one intron/exon boundary. Twenty percentage of the PCR volume was then analyzed on a $1.8 \%$ agarose gel in the presence of ethidium bromide and transferred to a $0.45 \mu \mathrm{m}$ Biodyne B transfer membrane from Pall Life Sciences (VWR International Ltd, Montreal, QC, Canada). The membrane was then dehydrated at $37^{\circ} \mathrm{C}$ for $30 \mathrm{~min}$, prehybridized with a buffer comprising $5 \times$ SSC, $5 \times$ Denhardt's solution, $50 \mathrm{mM} \mathrm{NaH}{ }_{2} \mathrm{PO}_{4}, 0.5 \%$ SDS, $200 \mu \mathrm{g} / \mathrm{ml}$ salmon sperm DNA, and $50 \%$ formamide, hybridized with ${ }^{32} \mathrm{P}$-labeled type $1 \mathrm{IL}-1 \mathrm{R}$ cDNA in the same buffer (without Denhardt's solution) and washed with $1 \times$ SSC, $0.2 \times$ SSC, and $0.1 \%$ SDS respectively, before being exposed to X-ray film (Kodak) for about $1 \mathrm{~h}$. 
Glyceraldehyde-phosphate dehydrogenase (GAPDH) amplification was used as control. PCR used $25 \%$ of the $\mathrm{RT}$ reaction volume as template in a final volume of $50 \mu \mathrm{l}$ with 25 pmol each primer (forward primer, $5^{\prime}$ TGA TGA CAT CAA GAA GGT GGT GAA G3 ${ }^{\prime}$; reverse primer, $5^{\prime}$ TCC TTG GAG GCC ATG TGG GCC AT 3'; amplimer size $240 \mathrm{bp}$ ), $0.2 \mathrm{mmol} / \mathrm{l} \mathrm{dNTPs}$, and $1 \mathrm{U}$ Vent DNA Polymerase. Amplification was performed for 30 cycles of $30 \mathrm{~s}$ denaturation $\left(95^{\circ} \mathrm{C}\right), 30 \mathrm{~s}$ annealing $\left(60^{\circ} \mathrm{C}\right)$, and 1 min primer extension $\left(72^{\circ} \mathrm{C}\right)$. These optimal conditions were determined following linearity tests using 10,25 , and $50 \%$ of the RT reaction volume.

Specificity of the amplification process was verified by Southern blot hybridization. A negative control (PCR in absence of cDNA) as well as a positive control (cDNA preparation from human endometrial adenocarcinoma Ishikawa cells expressing IL-1 RI) were included in each series of IL-1RI or GAPDH amplification. The quantity of the PCR products was determined by densitometric analysis of the intensity of the hybridization signal. The relative level of IL-1RI mRNA normalized to GAPDH mRNA was calculated, and the results were expressed as a percentage of the control value (positive control).

\section{Statistical analysis}

IL-1RI HSCORE, protein levels as measured by ELISA and western blotting, and mRNA levels as measured by RT-PCR followed a parametric distribution and were therefore analyzed using one-way ANOVA and the Bonferroni's post hoc test for multiple comparisons. Comparison of two groups was performed using the unpaired $t$ test. All analyses were performed using GraphPad Prism 3.0 (GraphPad Software, San Diego, CA, USA). Differences were considered as statistically significant for $P$ value $<0.05$.

\section{Results}

The first objective of this study was to assess the presence of IL-1RI in endometriotic lesions. Immunohistochemical analysis of IL-1RI expression showed a specific brownish immunostaining localized to specific compartments of endometriotic tissue. IL-1RI was found to be strongly expressed in glandular epithelial cells and stromal cells. Incubation of tissue sections with normal goat IgGs used at concentration equivalent to that of the primary goat polyclonal anti-human-IL-1RI antibody (negative control) did not result in any non-specific immunostaining (Fig. 1A). Human endometrial tissue from normal women, which according to our previous studies expresses IL-1RI (Bigonnesse et al. 2001), was used as positive control (data not shown). The intensity and distribution of IL-1RI immunostaining in endometriotic glands and stroma was then evaluated using HSCORE. As shown in Fig. 1B, HSCORE was signi-
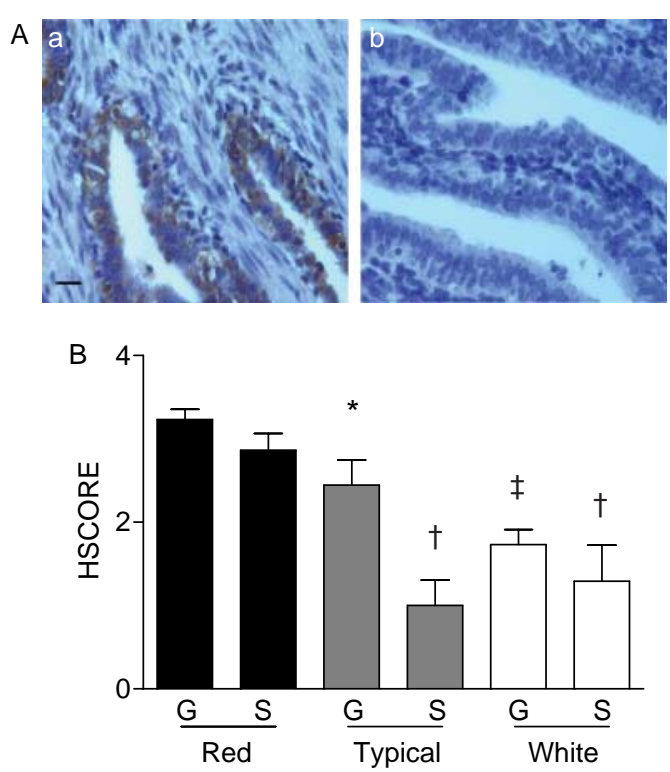

Figure 1 Immunohistochemical analysis of IL-1RI expression in endometriotic tissue. (A) Note the intense brown immunostaining in the glands and cell aggregates throughout the stroma in the presence of a polyclonal goat anti-human IL-1RI antibody (a) and the absence of such staining in the presence of goat IgGs used at concentration equivalent to that of the primary antibody (b; negative control); scale bar, $30 \mu \mathrm{m}$. (B) HSCORE in red $(n=7)$, typical $(n=6)$, and white $(n=5)$ endometriotic lesions. G, gland, S, stroma; *, ${ }^{+}$and ${ }^{\ddagger}$ significant difference with red lesions $(P<0.05,<0.01$, and $<0.001$ respectively) as analyzed by ANOVA and the Bonferroni's test for multiple comparisons.

ficantly higher in red endometriotic lesions as compared with typical black-blue or white endometriotic lesions, both in the glandular $(P<0.05$ and $<0.001$ respectively) and the stromal $(P<0.01$ and $<0.01$ respectively) compartments. Further analysis of these data did not show any statistically significant difference between endometriosis stages I, II and, III and IV. However, IL-1RI HSCORE was significantly higher in the proliferative than in the secretory phase of the menstrual cycle in endometriotic glands $(P<0.05)$. A tendency for a higher IL-1RI HSCORE in the proliferative compared with the secretory phase was also observed in the stroma, but the difference did not reach the level of statistical significance $(P=0.14)$.

To identify cells expressing IL-1RI in the stroma, dual immunofluorescent staining was performed using antibodies specific to IL-1RI, CD3, CD68, and VWF. Representative photomicrographs exhibited in Fig. 2 show a marked expression of IL-1RI in CD3-positive T-lymphocytes, CD68-positive macrophages, and vWFpositive endothelial cells.

To further quantify IL-1RI expression in endometriotic tissue, we measured IL-1RI concentrations in total protein extracts by ELISA. As shown in Fig. 3, IL-1RI protein concentrations were higher in red than in typical black-blue $(P<0.05)$ and white $(P<0.01)$ endometriotic 

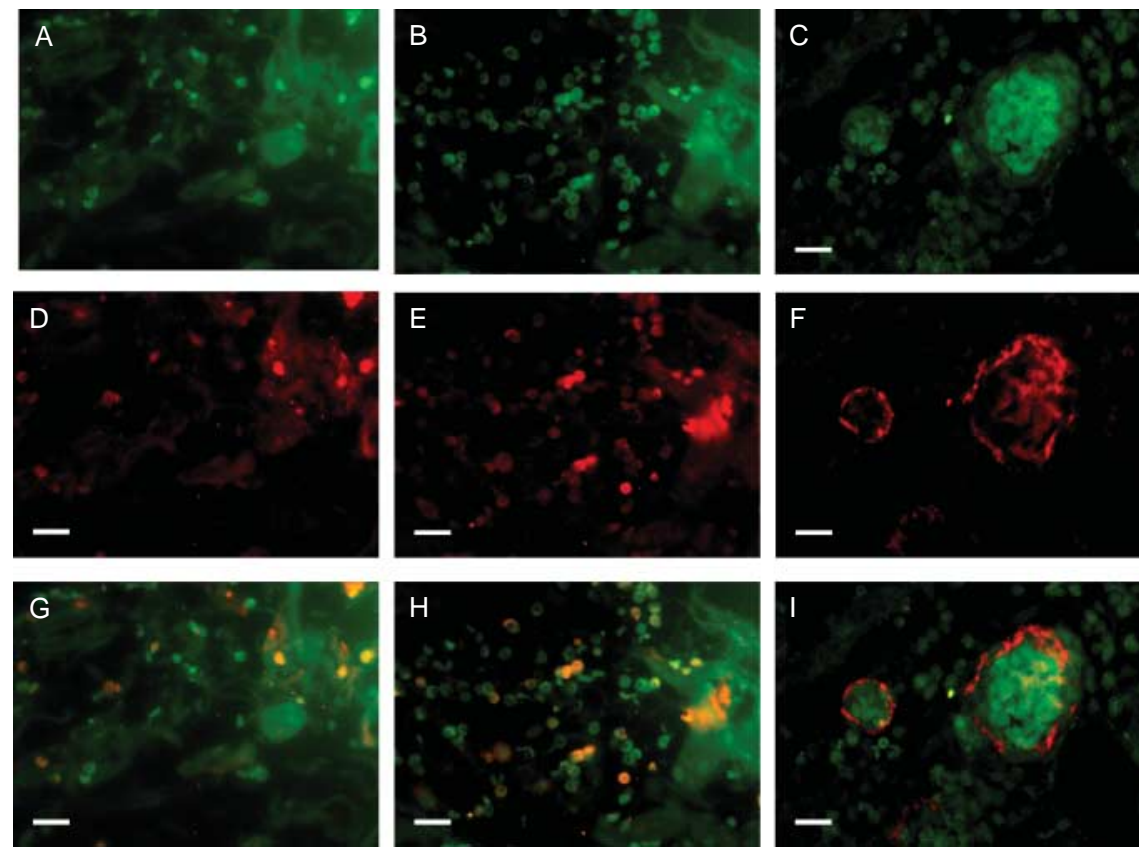

Figure 2 Dual-immunofluorescent staining of IL-1RI (A-C) and CD3 (D), CD68 (E), or vWF $(F)$ in endometriotic tissue. Tissue sections were incubated with goat polyclonal antihuman IL-1RI antibody and with mouse monoclonal anti-CD3, mouse monoclonal CD68, or mouse monoclonal anti-human vWF antibody. Sections were then incubated simultaneously with fluorescein isothiocyanate-conjugated donkey anti-goat antibody and rhodamine-conjugated sheep anti-mouse antibody to detect co-expression of IL-1 RI with CD3, CD68, or vWF. Note the expression of IL-1RI (green) in CD3-, CD68-, and vWFpositive T-lymphocytes, macrophages, and endothelial cells respectively (red). Superposition of fluorescein (green) and rhodamine (red) signals clearly shows co-expression (yellow signal) of IL-1RI with CD3 $(G=A+D)$, CD68 $(\mathrm{H}=\mathrm{B}+\mathrm{E})$, and $v W F(\mathrm{I}=\mathrm{C}+\mathrm{F})$. Scale bars, $30 \mu \mathrm{m}$. lesions. No statistically significant difference in IL-1RI protein expression between endometriosis stages I, II, and III and IV was observed. Analysis of IL-1RI protein expression according to the phase of the menstrual cycle showed higher expression in the proliferative than in the secretory phase $(P<0.05)$.

Western blot analysis of protein extracts from endometriotic tissue using a mouse monoclonal antihuman-IL-1RI antibody showed two specific bands at approximately 90 and $50 \mathrm{kDa}$, whose molecular weight are comparable to the known molecular weight of the membrane bound and the soluble form of IL-1RI (Fig. 1A). Densitometric analysis of IL-1RI bands in protein extracts from different types of endometriotic lesions showed no significant difference in the intensity of the $90 \mathrm{kDa}$ band between red, typical, and white endometriotic lesions. However, the $50 \mathrm{kDa}$ band was significantly more intense in red endometriotic lesions compared with typical endometriotic lesions $(P<0.05)$. The $50 \mathrm{kDa}$ band was also more intense in red compared with white endometriotic lesions, though the difference was not statistically significant ( $P=0.087$; Fig. 4B).

We further analyzed IL-1RI expression at the mRNA level using RT-PCR and Southern blotting. Figure 5A shows specific amplification of a 464 bp IL-1RI cDNA fragment from control Ishikawa cells and endometriotic tissue. Analysis of Southern blot data from different types of endometriotic lesions showed a more marked expression of IL-1RI mRNA in red than in typical black-blue $(P<0.05)$ and white $(P<0.01)$ lesions (Fig. 5B). Analysis of IL-1RI mRNA expression as to endometriosis stage and the menstrual cycle phase showed here again a more marked expression in the proliferative than the secretory phase $(P<0.05)$, whereas no statistically significant difference between endometriosis stages I, II, and III and IV was noted.

\section{Discussion}

Endometriosis might be a multifactorial disease and its etiology remains hypothetical. The presence of tissue outside the uterine cavity structurally and to some extent functionally comparable with the endometrium suggests that the condition, at least peritoneal endometriosis, results from implantation of exfoliated endometrium following retrograde menstruation (Sampson 1927).

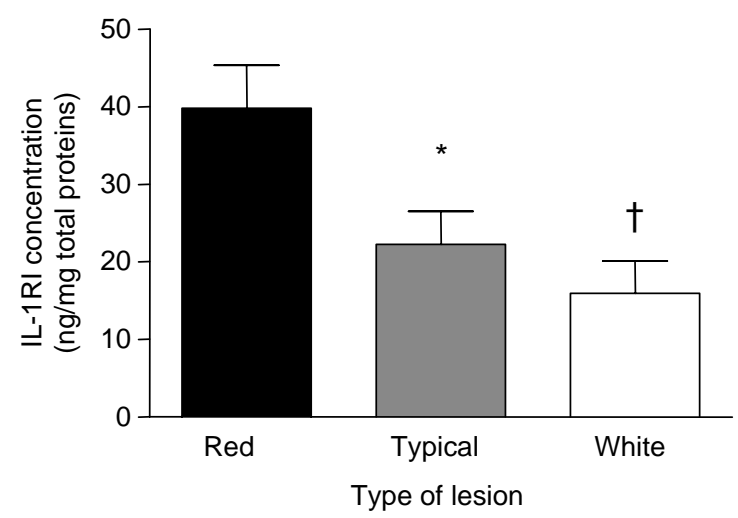

Figure 3 Graphical illustration of IL-1RI concentrations ( $\mathrm{ng} / \mathrm{mg}$ of total proteins) as measured by ELISA in endometriotic tissue. Endometriotic implants were classified according to their appearance at laparoscopy (red, $n=9$; typical, $n=13$; and white, $n=8) ;{ }^{*},{ }^{\dagger}$ significant difference with red lesions $(P<0.05$ and $<0.01$ respectively) as analyzed by ANOVA and the Bonferroni's test for multiple comparisons. 

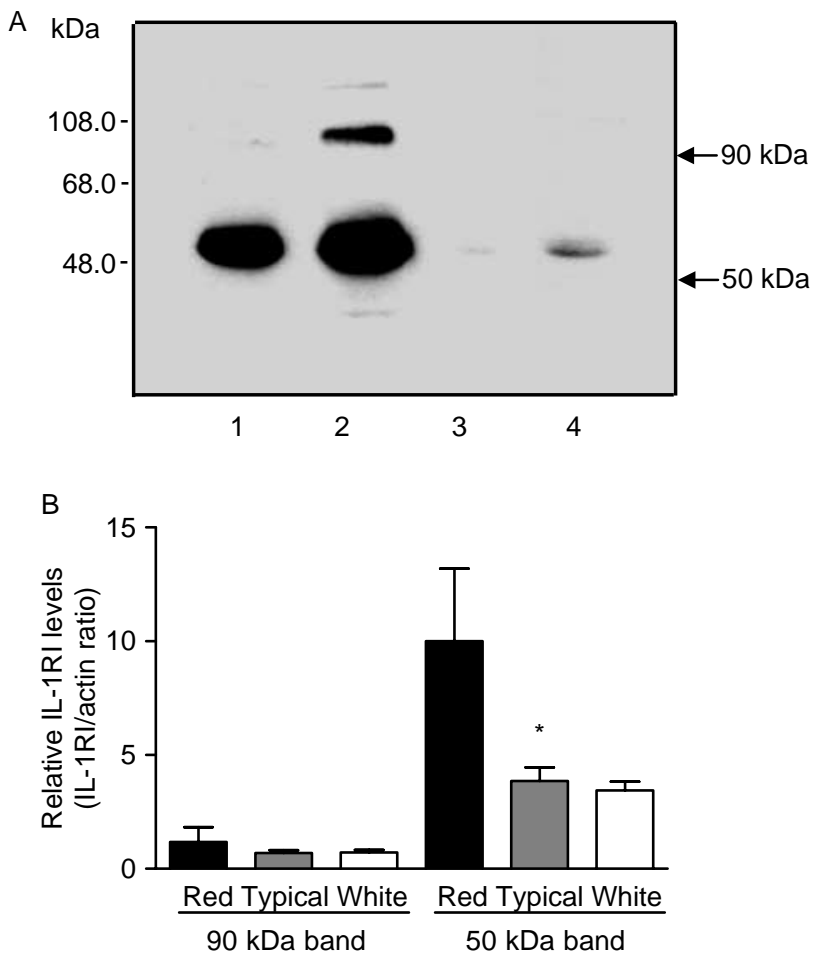

Figure 4 (A) Representative western blot analysis of IL-1RI expression in endometriotic tissue. Human recombinant soluble IL-1 RI (lanes 1 and 3) and endometriotic tissue protein extracts (lanes 2 and 4 ) were subjected to SDS-PAGE analysis and western blotting using a mouse monoclonal anti-human IL-1RI antibody (lanes 1-2) or an equivalent concentration of normal mouse IgGs instead of the primary antibody (lanes 3-4). The detected bands had an estimated apparent molecular weight of approximately 90 and $50 \mathrm{kDa}$. (B) Densitometric analysis of IL-1RI bands normalized to corresponding $\alpha$-actin bands from endometriotic lesions (red, $n=7$, typical, $n=14$; and white, $n=4$ ); *significant difference with red lesions $(P<0.05)$ as analyzed by ANOVA and the Bonferroni's test for multiple comparisons.

Accordingly, the ectopic development of endometrial tissue requires factors that are capable of remodeling the host tissue and sustaining endometrial tissue growth and the genesis of new microvessels.

Beside the intrinsic dysfunctions found in the eutopic endometrial tissue of women with endometriosis that may favor its ectopic development (Sharpe-Timms 2005), the establishment and progression of endometrial implants are dependent upon their interaction with and responsiveness to the stimuli present in their new environment. According to our and other previous studies, immune cells-derived cytokines, such as IL-1, may alone or in concert with estrogens, enhance the capability of ectopic endometrial cells to implant and develop into the host tissue, by inducing an angiogenic phenotype and stimulating the production of proinflammatory, growth, and tissue remodeling factors (Akoum et al. 2000, 2001, 2002, Taylor et al. 2002, Seli \& Arici 2003, Wu \& Ho 2003, Osteen et al. 2004). Furthermore, our and other previous studies showed
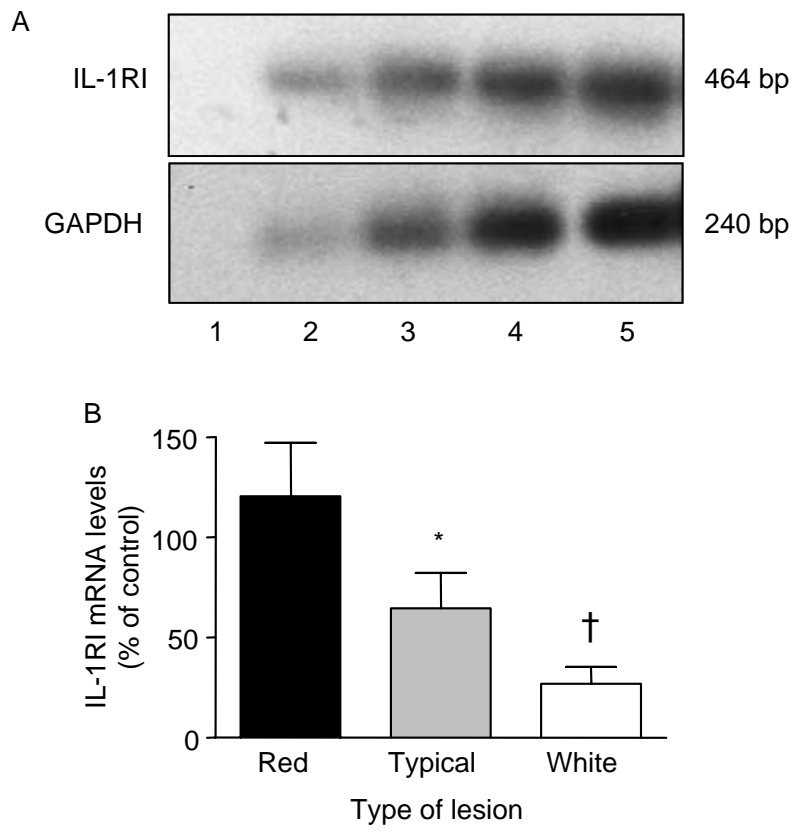

Figure 5 (A) Representative RT-PCR and Southern blot analysis of IL-1RI transcripts. Total RNA obtained from endometriotic tissue was reverse transcribed, amplified with IL-1RI (upper lanes) or GAPDH (lower lanes) primers, and hybridized with ${ }^{32}$ P-labeled corresponding probes, as described in Materials and Methods. Lane 1, negative control (PCR in the absence of cDNA); lanes 2-4, linearity test with different RT volumes; lane 5, positive control (cDNA preparation from human endometrial adenocarcinoma Ishikawa cell line which expresses IL-1RI). (B) Graphical illustration of IL-1RI mRNA steady-state levels in endometriotic tissues as assessed by RT-PCR and Southern blotting. The relative level of IL-1RI mRNA normalized to GAPDH mRNA was determined, and the results were expressed as percentage of control (positive control). Endometriotic tissues were classified according to their appearance at laparoscopy (red, $n=9$; typical, $n=9$; and white, $n=12) .{ }^{*},{ }^{\dagger}$ Significant difference with red lesions $(P<0.05$ and $<0.01$ respectively) as analyzed by ANOVA and the Bonferroni's test for multiple comparisons.

augmented sensitivity of endometriotic cells to the biological actions of IL-1 (Akoum et al. 1995, 1996, 2001, 2002, Lebovic et al. 2000), which may account for their ability to favor their own ectopic growth.

The present study showed that the functional receptor type I of IL-1, which mediates IL-1-induced cell activation, was expressed in ectopic endometrial tissue and that in different cell types. IL-1RI expression was quite obvious in endometriotic glandular and stromal cells. Dual immuofluorescence analysis further identified endothelial cells and inflammatory cells, such as macrophages and T-lymphocytes, as cells markedly expressing IL-1RI in the stroma. These findings are suggestive of a relationship between IL-1RI expression and the implant's activity considering that active endometriotic lesions show a more marked vascularization and leukocyte infiltration (Halme et al. 1987, Hill et al. 1988, Wiegerinck et al. 1993, Kokorine et al. 1997, Jones et al. 1998, McLaren 2000, Witz 2002, Taylor \& Mueller 2004). 
Endometriotic lesions can be classified according to their appearance and to their activity. In fact, lesions of the peritoneal lining of the pelvis have various macroscopic appearances, which reflect their age and/or activity. The red subtle lesions are more vascularized and have a higher epithelial mitotic index than the typical, puckered black or bluish peritoneal lesions, whereas the vascularization and the mitotic index are lower in the white lesions. Thus, red lesions are thought to correspond to the first, active stage of early implantation of endometrial glands and stroma, and would evolve toward the typical black or bluish lesion after enclosure beneath the peritoneal lining. The white lesions, which are believed to correspond to fibrotic quiescent lesions, show less vascularization and/or mitotic activity and represent less active forms of the disease (Nisolle et al. 1993, Wiegerinck et al. 1993, Kokorine et al. 1997, Nisolle et al. 1997). Interestingly, our present study revealed that IL-1RI expression was significantly higher in red than in typical black-blue or white endometriotic lesions. The protein expression, as assessed by HSCORE in endometriotic glands and stroma and measured by ELISA according to endometriotic lesion type was in keeping with that of mRNA as assessed by RT-PCR. This indicates that reduced expression of IL-1RI in more advanced endometriotic lesions occurs at the mRNA level, and is more likely due to a reduced mRNA synthesis and/or to mRNA instability than to translational and/or post-translational events. Of note is the $50 \mathrm{kDa}$ band, whose molecular weight corresponds to the soluble IL-1RI, which was significantly increased in red endometriotic lesions and markedly more intense than the $90 \mathrm{kDa}$ band corresponding to the membrane-bound receptor. This result is intriguing as soluble IL-1RI may, by interacting with IL-1, prevent cell activation via the membrane-bound signaling receptor. However, such a putative inhibitory property of soluble IL-1RI is hampered by its capability to interact as well with IL-1 receptor antagonist (IL-1 ra), which is a potent inhibitor of IL-1 (Boraschi et al. 1996). The inhibitory activity of IL-1ra was even shown to be enhanced by soluble IL-1RII and hindered by soluble IL-1RI (Burger et al. 1995). According to our and other previous data, endometriotic cells are highly sensitive and responsive to IL-1 (Akoum et al. 1995, 2000, 2001, 2002), and secrete increased levels of angiogenic factors compared with endometrial cells from normal women (Lebovic et al. 2000). Also, IL-1RI is, in contrast to the decoy inhibitory IL-1RII, slightly released in the culture medium of endometrial and endometriotic cells (personal data). Further studies will be required to elucidate whether the predominant detection of the soluble IL-1RI, compared to the membrane-bound IL-1RI, was rather due to or amplified by the experimental conditions.

The findings of the present study may have a great relevance since red endometriotic lesions are believed to represent the earliest and most active forms of endometriosis. Therefore, increased IL-1RI expression may reflect increased endometriotic cell receptivity to IL-1 in these lesions and a close relationship with the activity of the disease, and point to a process of cell activation, through IL-1 signaling, that takes place in the ectopic endometrial tissue, particularly in its earliest forms. In the present study, no statistically significant difference in IL-1RI expression between endometriosis stages I, II, and III and IV was found. Although more samples are required to ascertain the relationship between the evolution of endometriosis stage and IL-1RI expression, our data suggest that IL-1RI expression is more related to the lesion's type and activity than to endometriosis stage.

Ectopic implantation and growth of endometrial tissue following retrograde menstruation requires new active tissue remodelling and blood supply to enable a successful implantation of the migrating tissue in the peritoneal cavity. Early and most active endometriotic lesions are markedly vascularized and increased vascularization is seen at the implant's surface as well as also in the surrounding peritoneal tissue (Nisolle et al. 1993, 1997, Wiegerinck et al. 1993, Kokorine et al. 1997), suggesting that endometriotic implants are capable of inducing its own neovascularization by deriving local microvasculature. Evidence available to date supports a central role for activated immune cells, particularly macrophages and their secretory products, in the progression of endometriotic implants and offers an immunological explanation for the neovascularization that surrounds these lesions (Taylor et al. 2002). IL-1 is a prototypic example of an activated peritoneal macrophage secretory product in endometriosis. Macrophages from women with endometriosis were found to secrete elevated levels of IL-1 (Zeller et al. 1987). Elevated concentrations of IL-1 were found in the peritoneal fluid of women suffering from endometriosis (Fakih et al. 1987, Mori et al. 1992, Taketani et al. 1992). IL-1 would have more pronounced effects on adhesion in endometriosis (Sillem et al. 1999). Activation and recruitment of immune cells into endometriotic implants can be mediated by other secreted cytokines and chemokines such as MCP-1, RANTES, IL-6, and IL-8, which were found to be up-regulated by IL- 1 in endometriotic cells (Akoum et al. 1995, 1996, 2001, 2002) and could in turn promote IL-1 secretion by activated immune cells. IL-1 induces secretion of IL-8 and IL-6, which exhibit proangiogenic properties (Akoum et al. 1996, 2001). Data from Lebovic et al. (2000) showed an enhanced production of angiogenic molecules such as vascular endothelial growth factor (VEGF) and IL-6 in response to IL-1 $\beta$ in endometriotic cells, as compared with endometrial cells from normal endometrium, and increased expression of IL-1RI mRNA, suggesting a role for IL-1 $\beta$ ligand binding and signaling via IL-1RI. Therefore, in view of IL-1 biological effects, marked IL-1RI expression in active and early endometriosis lesions may play a 
significant role in promoting a successful implantation of endometrial tissue in the earliest steps of endometriosis following retrograde menstruation.

In the present study, we analyzed IL-1RI expression according to the menstrual cycle phase and found that both protein and mRNA expression of the receptor were significantly higher in the proliferative than in the secretory phase of the menstrual cycle. Interestingly, previous studies from our and other laboratories showed that IL-1RI expression in the endometrial tissue was particularly elevated in the late secretory phase of the menstrual cycle (Simon et al. 1993, Bigonnesse et al. 2001). This suggests that endometrial tissue debris, which migrate into the peritoneal cavity at the end of the menstrual cycle and may develop into endometriosis lesions, express the highest levels of IL-1RI, and may therefore be more responsive to IL-1. This may lead to an exaggerated peritoneal inflammatory response; however, it is still to be determined whether IL-1RI expression in the menstrual endometrial tissue is more elevated in women with endometriosis than in normal women. Moreover, it is quite possible that red hemorrhagic implants, which follow the cyclical changes of the menstrual cycle and express higher levels of IL-1RI in the proliferative phase, would produce higher levels of growth, mitogenic, and proinflammatory factors in response to IL-1, thereby favoring tissue growth and implantation in the host tissue during that phase. In agreement with this hypothesis is the finding that VEGF concentrations in the peritoneal fluid of women with endometriosis are significantly higher in the peritoneal fluid during the proliferative phase compared with the secretory phase (McLaren et al. 1996).

In conclusion, the present study showed IL-1RI expression in various cell types throughout endometriotic tissue and its marked expression in lesions representing the earliest and most active stages of the disease. In view of IL-1-mediated changes in endometriotic cells, this may play a significant role in the initial steps of ectopic endometrial tissue growth and the pathophysiology of endometriosis. Future investigations are needed to determine whether the up-regulation of the IL-1RI is a result of endometrial cell interaction with a cytokine-rich environment in the ectopic sites, as IL-1 was shown to up-regulate its own receptor (Simon et al. 1994), and/or the successful selection of highly cytokine-sensitive endometrial cells displaced into the peritoneal cavity by retrograde menstruation.

\section{Acknowledgements}

The authors wish to thank the group of investigation in gynecology (Drs André Lemay, François Belhumeur, Jean-Yves Fontaine, Jacques Mailloux, and Marc Villeneuve) for patient evaluation and providing endometriotic tissue samples, François Bigonnesse, Nathalie Bourcier, Madeleine Desaulniers, Monique Longpré, Johanne Pelletier and Sylvia
Pleau for technical assistance. This work was supported by grant MOP-14638 to Ali Akoum from The Canadian Institutes for Health Research. A A is Chercheur National from the Fonds de la Recherche en Santé du Québec (FRSQ). The authors declare that there is no conflict of interest that would prejudice the impartiality of this scientific work.

\section{References}

Akoum A, Lemay A, Brunet C \& Hebert J 1995 Cytokine-induced secretion of monocyte chemotactic protein-1 by human endometriotic cells in culture. The Groupe D'Investigation en Gynecologie. American Journal of Obstetrics and Gynecology 172 594-600.

Akoum A, Lemay A, Paradis I, Rheault N \& Maheux R 1996 Secretion of interleukin- 6 by human endometriotic cells and regulation by proinflammatory cytokines and sex steroids. Human Reproduction $112269-2275$.

Akoum A, Jolicoeur C \& Boucher A 2000 Estradiol amplifies interleukin-1-induced monocyte chemotactic protein-1 expression by ectopic endometrial cells of women with endometriosis. Journal of Clinical Endocrinology and Metabolism 85 896-904.

Akoum A, Lawson C, McColl S \& Villeneuve M 2001 Ectopic endometrial cells express high concentrations of interleukin (IL)-8 in vivo regardless of the menstrual cycle phase and respond to oestradiol by up-regulating IL-1-induced IL-8 expression in vitro. Molecular Human Reproduction 7 859-866.

Akoum A, Lemay A \& Maheux R 2002 Estradiol and interleukin-1beta exert a synergistic stimulatory effect on the expression of the chemokine regulated upon activation, normal T cell expressed, and secreted in endometriotic cells. Journal of Clinical Endocrinology and Metabolism 87 5785-5792.

Anonymous 1997 Revised american society for reproductive medicine classification of endometriosis: 1996. Fertility and Sterility 67 817-821.

Barlow DH \& Kennedy S 2005 Endometriosis: new genetic approaches and therapy. Annual Review of Medicine 56 345-356.

Bedaiwy MA \& Falcone T 2003 Peritoneal fluid environment in endometriosis. Clinicopathological implications. Minerva Ginecologica 55 333-345.

Bergqvist A, Bruse C, Carlberg M \& Carlstrom K 2001 Interleukin 1 beta, interleukin-6, and tumor necrosis factor-alpha in endometriotic tissue and in endometrium. Fertility and Sterility 75 489-495.

Bigonnesse F, Labelle Y \& Akoum A 2001 Triphasic expression of interleukin-1 receptor type I in human endometrium throughout the menstrual cycle of fertile women and women with unexplained infertility. Fertility and Sterility 75 79-87.

Boraschi D, Bossu P, Macchia G, Ruggiero P \& Tagliabue A 1996 Structure-function relationship in the IL-1 family. Frontiers in Bioscience $1 \mathrm{~d} 270-\mathrm{d} 308$.

Burger D, Chicheportiche R, Giri JG \& Dayer JM 1995 The inhibitory activity of human interleukin-1 receptor antagonist is enhanced by type II interleukin-1 soluble receptor and hindered by type I interleukin-1 soluble receptor. Journal of Clinical Investigation 96 38-41.

D'Hooghe TM, Kyama C, Debrock S, Meuleman C \& Mwenda JM 2004 Future directions in endometriosis research. Annals of the New York Academy of Sciences 1034 316-325.

Fakih H, Baggett B, Holtz G, Tsang KY, Lee JC \& Williamson HO 1987 Interleukin-1: a possible role in the infertility associated with endometriosis. Fertility and Sterility 47 213-217.

Giudice LC 2003 Genomics' role in understanding the pathogenesis of endometriosis. Seminars in Reproductive Medicine 21 119-124.

Giudice LC, Tazuke SI \& Swiersz L 1998 Status of current research on endometriosis. Journal of Reproductive Medicine 43 252-262. 
Halme J, Becker S \& Haskill S 1987 Altered maturation and function of peritoneal macrophages: possible role in pathogenesis of endometriosis. American Journal of Obstetrics and Gynecology 156 783-789.

Harada T, Iwabe T \& Terakawa N 2001 Role of cytokines in endometriosis. Fertility and Sterility 76 1-10.

Hill JA, Faris HM, Schiff I \& Anderson DJ 1988 Characterization of leukocyte subpopulations in the peritoneal fluid of women with endometriosis. Fertility and Sterility $\mathbf{5 0} 216-222$.

Jolicoeur C, Boutouil M, Drouin R, Paradis I, Lemay A \& Akoum A 1998 Increased expression of monocyte chemotactic protein-1 in the endometrium of women with endometriosis. American Journal of Pathology 152 125-133.

Jones RK, Bulmer JN \& Searle RF 1998 Phenotypic and functional studies of leukocytes in human endometrium and endometriosis. Human Reproduction Update 4 702-709.

Kokorine I, Nisolle M, Donnez J, Eeckhout Y, Courtoy PJ \& Marbaix E 1997 Expression of interstitial collagenase (matrix metalloproteinase-1) is related to the activity of human endometriotic lesions. Fertility and Sterility 68 246-251.

Lebovic DI, Bentzien F, Chao VA, Garrett EN, Meng YG \& Taylor RN 2000 Induction of an angiogenic phenotype in endometriotic stromal cell cultures by interleukin-1beta. Molecular Human Reproduction 6 269-275.

Lebovic DI, Mueller MD \& Taylor RN 2001a Immunobiology of endometriosis. Fertility and Sterility 75 1-10.

Lebovic DI, Chao VA, Martini JF \& Taylor RN $2001 b$ IL-1 beta induction of RANTES (regulated upon activation, normal T cell expressed and secreted) chemokine gene expression in endometriotic stromal cells depends on a nuclear factor-kappaB site in the proximal promoter. Journal of Clinical Endocrinology and Metabolism 86 4759-4764.

McLaren J 2000 Vascular endothelial growth factor and endometriotic angiogenesis. Human Reproduction Update 6 45-55.

McLaren J, Prentice A, Charnock-Jones DS \& Smith SK 1996 Vascular endothelial growth factor (VEGF) concentrations are elevated in peritoneal fluid of women with endometriosis. Human Reproduction 11 220-223.

Mori H, Sawairi M, Nakagawa M, Itoh N, Wada K \& Tamaya T 1992 Expression of interleukin-1 (IL-1) beta messenger ribonucleic acid (mRNA) and IL-1 receptor antagonist mRNA in peritoneal macrophages from patients with endometriosis. Fertility and Sterility $\mathbf{5 7}$ 535-542.

Nisolle M, Casanas-Roux F, Anaf V, Mine JM \& Donnez J 1993 Morphometric study of the stromal vascularization in peritoneal endometriosis. Fertility and Sterility 59 681-684.

Nisolle M, Casanas-Roux F \& Donnez J 1997 Immunohistochemical analysis of proliferative activity and steroid receptor expression in peritoneal and ovarian endometriosis. Fertility and Sterility 68 912-919.

Noyes RW, Hertig AT \& Rock J 1975 Dating the endometrial biopsy. American Journal of Obstetrics and Gynecology 122 262-263.

Olive DL \& Schwartz LB 1993 Endometriosis. New England Journal of Medicine 328 1759-1769.

Osteen KG, Igarashi TM, Yeaman GR \& Bruner-Tran KL 2004 Steroid and cytokine regulation of matrix metalloproteinases and the pathophysiology of endometriosis. Gynecologic and Obstetric Investigation $\mathbf{5 7}$ 53-54.

Sampson J 1927 Peritoneal endometriosis due to menstrual dissemination of endometrial tissue into the peritoneal cavity. American Journal of Obstetrics and Gynecology 14 422-469.
Seli E \& Arici A 2003 Endometriosis: interaction of immune and endocrine systems. Seminars in Reproductive Medicine 21 135-144.

Sharpe-Timms KL 2005 Defining endometrial cells: the need for improved identification at ectopic sites and characterization in eutopic sites for developing novel methods of management for endometriosis. Fertility and Sterility 84 38-39 (Discussion 38-39).

Sillem M, Prifti S, Monga B, Arslic T \& Runnebaum B 1999 Integrinmediated adhesion of uterine endometrial cells from endometriosis patients to extracellular matrix proteins is enhanced by tumor necrosis factor alpha (TNF alpha) and interleukin-1 (IL-1). European Journal of Obstetrics, Gynecology, and Reproductive Biology 87 123-127.

Simon C, Piquette GN, Frances A \& Polan ML 1993 Localization of interleukin-1 type I receptor and interleukin-1 beta in human endometrium throughout the menstrual cycle. Journal of Clinical Endocrinology and Metabolism 77 549-555.

Simon C, Piquette GN, Frances A, el-Danasouri I, Irwin JC \& Polan ML 1994 The effect of interleukin-1 beta (IL-1 beta) on the regulation of IL-1 receptor type I messenger ribonucleic acid and protein levels in cultured human endometrial stromal and glandular cells. Journal of Clinical Endocrinology and Metabolism 78 675-682.

Subramaniam S, Stansberg C \& Cunningham C 2004 The interleukin 1 receptor family. Developmental and Comparative Immunology 28 415-428.

Taketani Y, Kuo TM \& Mizuno M 1992 Comparison of cytokine levels and embryo toxicity in peritoneal fluid in infertile women with untreated or treated endometriosis. American Journal of Obstetrics and Gynecology 167 265-270.

Taylor RN \& Mueller MD 2004 Anti-angiogenic treatment of endometriosis: biochemical aspects. Gynecologic and Obstetric Investigation $\mathbf{5 7}$ 54-56.

Taylor RN, Lebovic DI \& Mueller MD 2002 Angiogenic factors in endometriosis. Annals of the New York Academy of Sciences 955 89-100 (Discussion 118, 396-406).

Tseng JF, Ryan IP, Milam TD, Murai JT, Schriock ED, Landers DV \& Taylor RN 1996 Interleukin-6 secretion in vitro is up-regulated in ectopic and eutopic endometrial stromal cells from women with endometriosis. Journal of Clinical Endocrinology and Metabolism $\mathbf{8 1}$ 1118-1122.

Ulukus M \& Arici A 2005 Immunology of endometriosis. Minerva Ginecologica 57 237-248.

Wiegerinck MA, Van Dop PA \& Brosens IA 1993 The staging of peritoneal endometriosis by the type of active lesion in addition to the revised American fertility society classification. Fertility and Sterility 60 461-464.

Witz CA 2002 Pathogenesis of endometriosis. Gynecologic and Obstetric Investigation 53 52-62.

Wu MY \& Ho HN 2003 The role of cytokines in endometriosis. American Journal of Reproductive Immunology 49 285-296.

Zeller JM, Henig I, Radwanska E \& Dmowski WP 1987 Enhancement of human monocyte and peritoneal macrophage chemiluminescence activities in women with endometriosis. American Journal of Reproductive Immunology Microbiology 13 78-82.

Received 27 January 2006

First decision 29 March 2006

Revised manuscript received 24 July 2006

Accepted 4 September 2006 